\title{
Study of Diffusion Influence Materials of Copper-Zinc- Steel on the Hardness and Micro Hardness under Heat Treatment.
}

\author{
Ali Adwan AL Katawy \\ Department of Material Engineering, College of engineering, University of Diyala \\ aliadwanh@gmail.com
}

\begin{abstract}
Low melting metals like zinc used in this research to promote increasing of diffusion process with presence of pure powder of copper., this metals have good corrosion resistance in chemical and environmental conditions by making thin film to hardening surface of rod of stainless steel18/8Ni-Cr under heat treatment condition at $890 \mathrm{c}$ above eutectic line to reached austerity zone and under this line at ${ }^{0}, 600 \mathrm{c}$ to obtained re-crystallization annealing and $400 \mathrm{c}^{0}$ at sufficient time 90 min.chemical composition ,hardness ,micro-hardness ,and micro structures were investigated to track the effectiveness of diffusion zinccopper melting in different s points.
\end{abstract}

Keyword: Heat treatments, re-crystallization, Micro Hardness, stainless steel.

Paper History: (Received: 15/1/2018; Accepted:

$13 / 2 / 2018)$

\section{1- Introduction}

Ordinary uses metals and ceramics materials as a coated films to protect steel alloys part with different methods like galvanization and immersion method in melting metals especially when this part exposed to chemical and environmental condition. These materials used in different thickness on the external surface according to working requirement. But in the same time thickness of coating materials gives new base materials surroundings of the base metals. Hardness one of important properties on the external surface of metals especially moving or rotating parts needed wear resistance. This corrosion resistance protecting by uses ceramics or powder metallurgy coating, but when we use this part to chemical condition coating of low melting metals should be less cost and become economical. This method with presence of heating or thermal condition contribute to obtained diffusion with different proportion depend on the time and heating condition (Fick's laws of diffusion )[1].Zinc and copper alloys are uses for long periods as a protection coated metals with steels alloys at different percentage if the weight and cost important depend on the ( $\mathrm{Zn}-\mathrm{Fe})$ and $(\mathrm{Zn}$ $\mathrm{Cu}$ ) phase diagrams as shown in the figure[1], we uses powders of 95\%zinc and5\% coppers metals to obtained melting alloys surrounding by rod of steel depend on fig.[2] .diffusion of atomic zinc and copper will be expected to gives thin film change the hardness and micro hardness of base metals so that what study in this research

\section{Experimental Work}

\subsection{Material Uses:}

A-Rod $\varnothing 5 \mathrm{~mm} \times 15 \mathrm{~mm}$ stainless steel $18 / 8$.

B-powder95g from pure zinc metal.

C-powder $5 \mathrm{~g}$ from pure copper metal.

D-quartz tube $(\varnothing 20 \mathrm{~mm} \times 100 \mathrm{~mm})$.

\subsection{Preparation sample:}

Mixed powder of zinc and copper before putting it together with rod of steel in the quartz tube.

1. Heating sample in the furnace at $890 \mathrm{c}^{0}$ for $30 \mathrm{~min}$.

2. Cooling sample to $600 \mathrm{c}^{0}$ in the furnace for $30 \mathrm{~min}$.

3. Cooling sample to $400 \mathrm{c}^{0}$ in the furnace for $30 \mathrm{~min}$.

4. Cooling it at room temperature and polished sample after cutting it in the middle.

5. Examine hardness, micro-hardness, micro-structure, and chemical composition by using (CSM instrument).

\section{Results and Discussion}

1. Point 1. At rod of stainless steel before heat treatment.

2. Point 2.At $2 \mu \mathrm{m}$ surrounding steel rod (zinc -copper melting zone) after heat. Treatment.

3. Point 3.At $5 \mu \mathrm{m}$ surrounding steel rod after heat treatment.

4. Hardness and micro-hardness results at the steel rod and surrounding melting zone shown in the table-3

5. Micro-structure of stainless steel rod and surrounding Zn-cu melting alloy.

Test point were selected surrounding and on the st.steel rod to investigated diffusion $\mathrm{Zn}$-cu affected under heat treatment at $890 \mathrm{c}^{0}$ where obtained austenite phase as shown in fig. 3 , in this temperature diffusion process was take place in very fast due to energy and dissolved carbides of cementite $(\mathrm{Fe} 3 \mathrm{C})$.At the same time at $600 \mathrm{c}^{0}$ has enough time to produce coating layer surrounding stainless steel 
rod or matrtenstic phase at room temperature where investigated in table- 1 and table- 2 .

So hardness and micro-hardness results were clear decreasing because of influence of zinc and copper diffusion through martensite crystals .That can be clearly seen at results of chemical composition of points selected to investigation.as shown in results in table -3 .

This process also known as homogenizing annealing, is employed to remove any structural non-uniformity .Dendrites, columnar grains and chemical in homogenize are generally observed in the case of ingots, heavy plain carbon steel casting, and high alloy steel castings. These defects promote brittleness and reduce ductility and toughness of steel. In diffusion annealing treatment, steel is heated sufficiently above the upper critical

Temperature (say, $1000-1200^{\circ} \mathrm{C}$ ), and is held at this temperature for prolonged periods, usually 10-20 hours, followed by slow cooling.

\section{Conclusions}

1. To obtained homogenize coating film and surface hardening goes with protection condition we must investigate the heat treatment and temperature used depending on percentage of zinc and copper.

2. Low melting metals like zinc or bismuth elements can be used as a coating film of steel and stainless steel with copper to produce inter metallic phase to promote increasing corrosion resistance( fig. 4 and fig-5) this produced by diffuse copper and zinc in steel as shown in (fig 6 and fig 7).

3. Wear resistance decreased at moving and rotating parts due to films obtained of low melting metals.

\section{Acknowledgment}

I would like to acknowledge receipt of Ural Federal University Physics of Metals and Heat Treatment department Yekaterinburg, Russia.

\section{References}

[1] V.I. Bokshitskii, A.M. Glezer, E.K. Zakharov, G.A. SveshnikovaMetal Sci. Heat Treat. 39 (1997), pp. 38 41.

[2] T.T. Sasaki, M. Barkey, G.B. Thompson, Y. Syarif, D. Fox.

[3] Mater. Sci. Eng. A, B. Tuck, Atomic Diffusion in IIIV Semiconductors (Hilger, Bristol, 1988), 528 (2011), pp. 2974-2981.

[4] D. B. Darby, DPhil. Thesis, Oxford University, Department of Metallurgy and Science of Materials (1979)

[5] A. G. Gad-Allah, M. M. Abou-Romia, M. W. Badawy and H. H. Rehan. Passivity of?-brass (Cu?Zn/67?33) and its breakdown in neutral and alkaline solutions containing halide ions. Journal of Applied Electrochemistry, (1991)21:9, 829-836.

[6] T.M.H. Saber and A.A. El Warraky. (1993) Electrochemical and spectroscopic studies on dezincification of $\alpha$-brass. Desalination 93:1-3, 473 486. Online publication date: 1-Aug-1993.

[7] R.K. Dinnappa and S.M. Mayanna The dezincification of brass and its inhibition in acidic chloride and sulphate solutions. Corrosion Science 27:4, . (1987) 349-361. Online publication date: 1-Jan-1987.

[8] L. Horner and E. Pliefke. (1986) Inhibitoren der Korrosion 31 (1). Beitrag zur Inhibierung der Korrosion von Zink und Messing. Materials and Corrosion/Werkstoffe und Korrosion37:8, 457-463. 


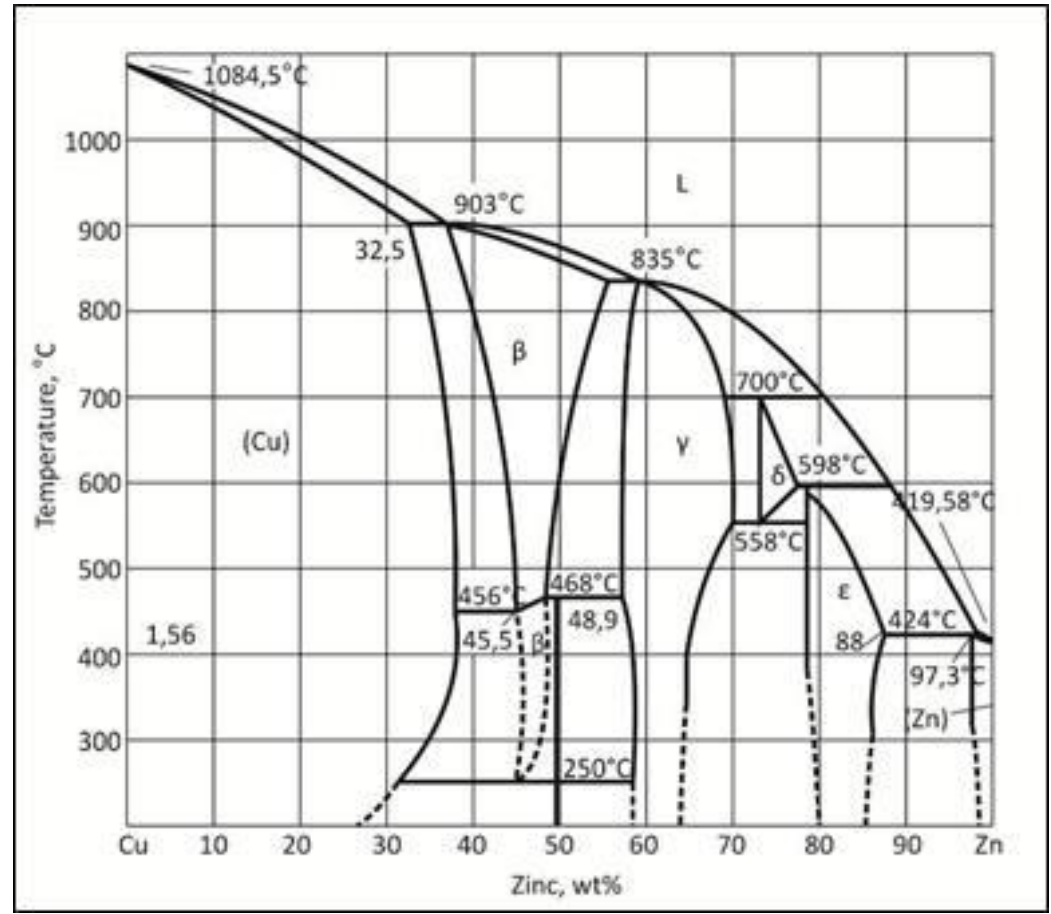

Fig. 1

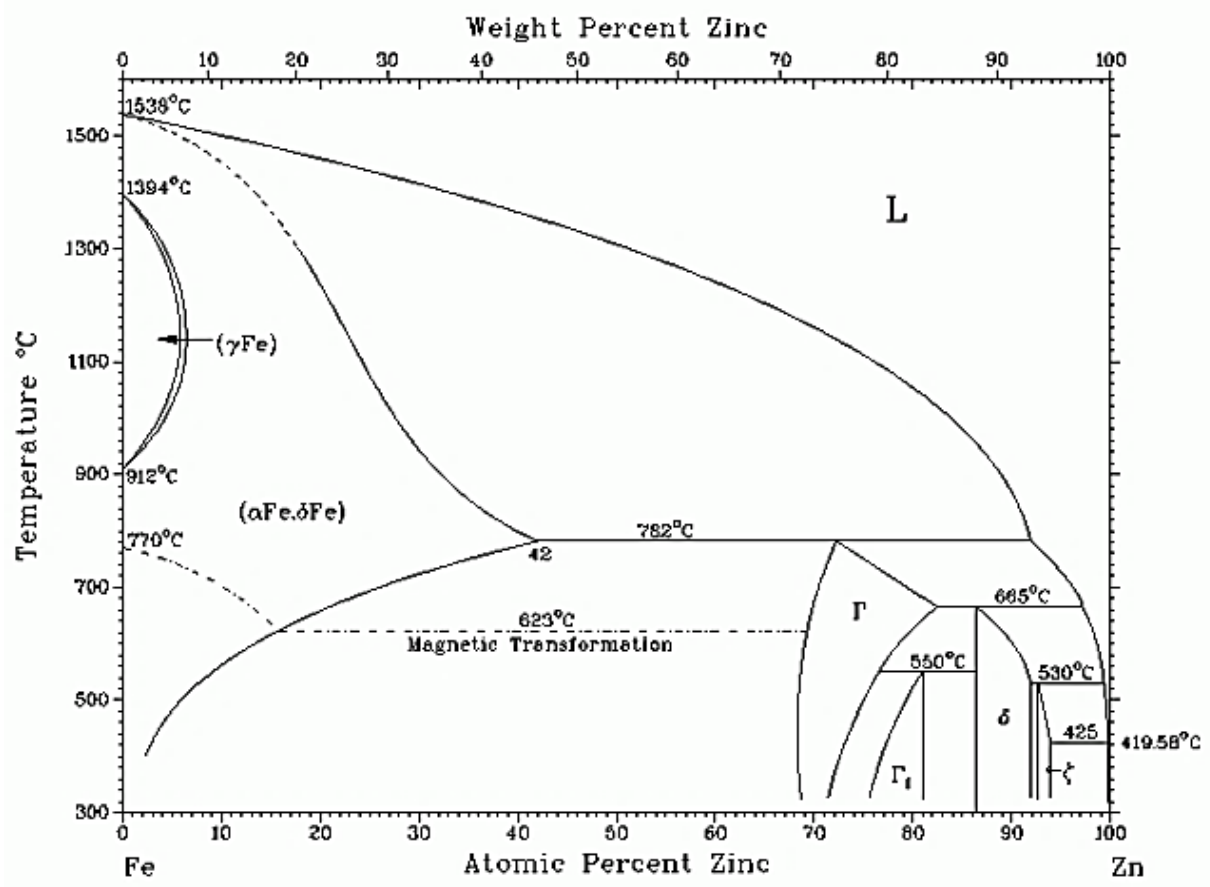

Fig.2 


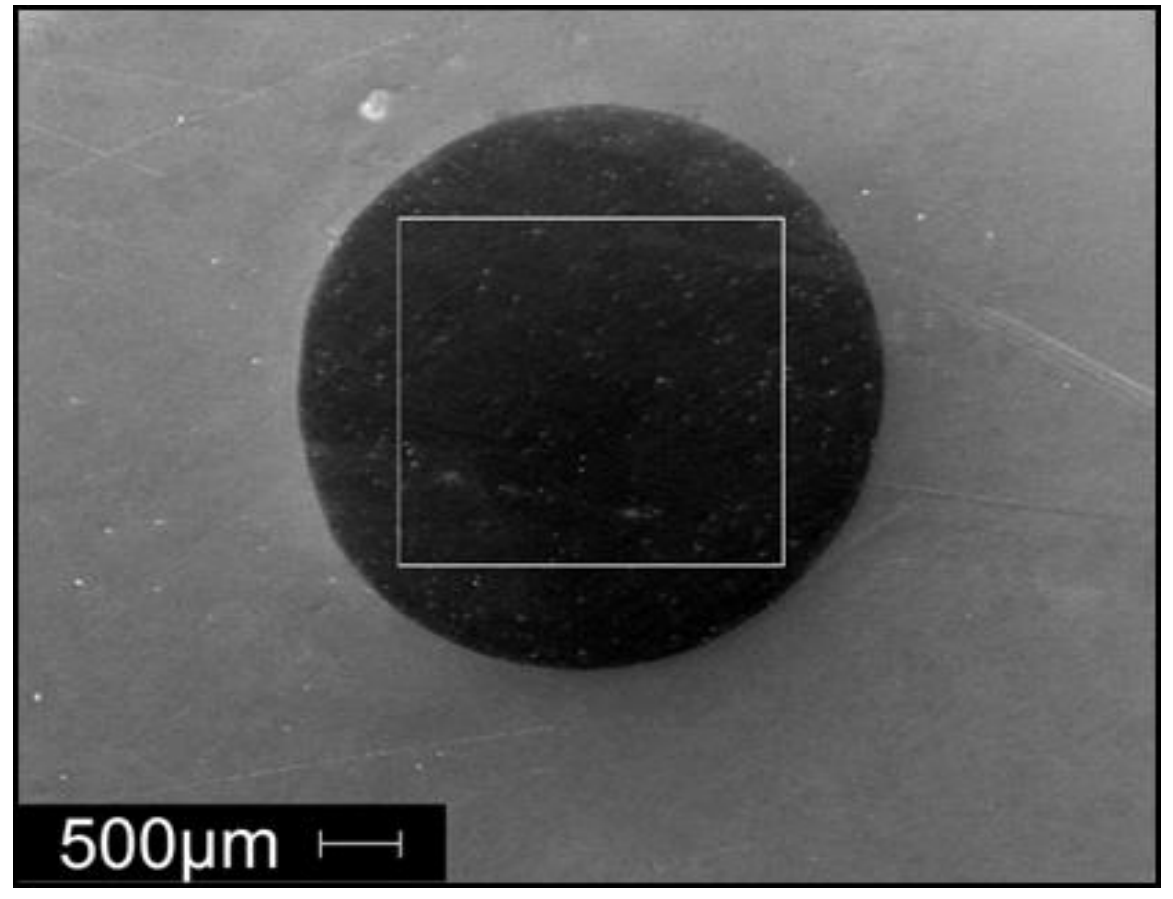

Fig.3

Table.1: Chemical co. before $h . t$.

\begin{tabular}{|c|c|c|}
\hline Element & Wt\% & At\% \\
\hline SiK & 00.74 & 01.44 \\
\hline TiK & 00.80 & 00.92 \\
\hline CrK & 18.09 & 19.09 \\
\hline MnK & 01.54 & 01.54 \\
\hline FeK & 69.76 & 68.54 \\
\hline NiK & 09.07 & 08.47 \\
\hline
\end{tabular}

Table.2: Chemical co. after h.t.

\begin{tabular}{|c|c|c|}
\hline Element & Wt \% & At\% \\
\hline SiK & $\mathbf{0 0 . 1 9}$ & $\mathbf{0 0 . 4 4}$ \\
\hline TiK & $\mathbf{0 0 . 2 4}$ & $\mathbf{0 0 . 3 2}$ \\
\hline CrK & $\mathbf{0 1 . 6 3}$ & $\mathbf{0 2 . 0 0}$ \\
\hline MnK & $\mathbf{0 0 . 3 1}$ & $\mathbf{0 0 . 3 6}$ \\
\hline FeK & $\mathbf{0 7 . 0 1}$ & $\mathbf{0 8 . 0 3}$ \\
\hline NiK & $\mathbf{0 1 . 3 3}$ & $\mathbf{0 1 . 4 5}$ \\
\hline CuK & $\mathbf{0 1 . 0 4}$ & $\mathbf{0 1 . 0 5}$ \\
\hline ZnK & $\mathbf{8 8 . 2 4}$ & $\mathbf{8 6 . 3 4}$ \\
\hline
\end{tabular}


Table.3: Chemical co.

\begin{tabular}{|c|c|c|}
\hline Element & Wt\% & At\% \\
\hline CrK & 00.93 & 01.15 \\
\hline FeK & 03.94 & 04.57 \\
\hline NiK & 00.53 & 00.59 \\
\hline CuK & 03.85 & 03.92 \\
\hline ZnK & 90.75 & 89.78 \\
\hline
\end{tabular}

Table.4: Hardness and micro hardness before and after heat treatment

\begin{tabular}{|c|c|c|c|}
\hline $\begin{array}{c}\text { Micro hardness of } \\
\text { St .steel rod before } \\
\text { H.T HV }\end{array}$ & $\begin{array}{c}\text { Micro hardness } \\
\text { after H .T+ZN+CU } \\
\text { HV }\end{array}$ & $\begin{array}{c}\text { Hardness HRC } \\
\text { before H.T }\end{array}$ & $\begin{array}{c}\text { Hardness HRC after } \\
\text { H.T }+ \text { ZN+CU }\end{array}$ \\
\hline 400 & 290.5 & 37.0 & 23 \\
\hline 461 & 359.8 & 38 & 23 \\
\hline 430.5 & 334.2 & 40.2 & 24 \\
\hline 462.6 & 299.8 & 38 & 22 \\
\hline 440.5 & 355 & 45 & 26 \\
\hline 450 & 289.2 & 39 & 23 \\
\hline
\end{tabular}

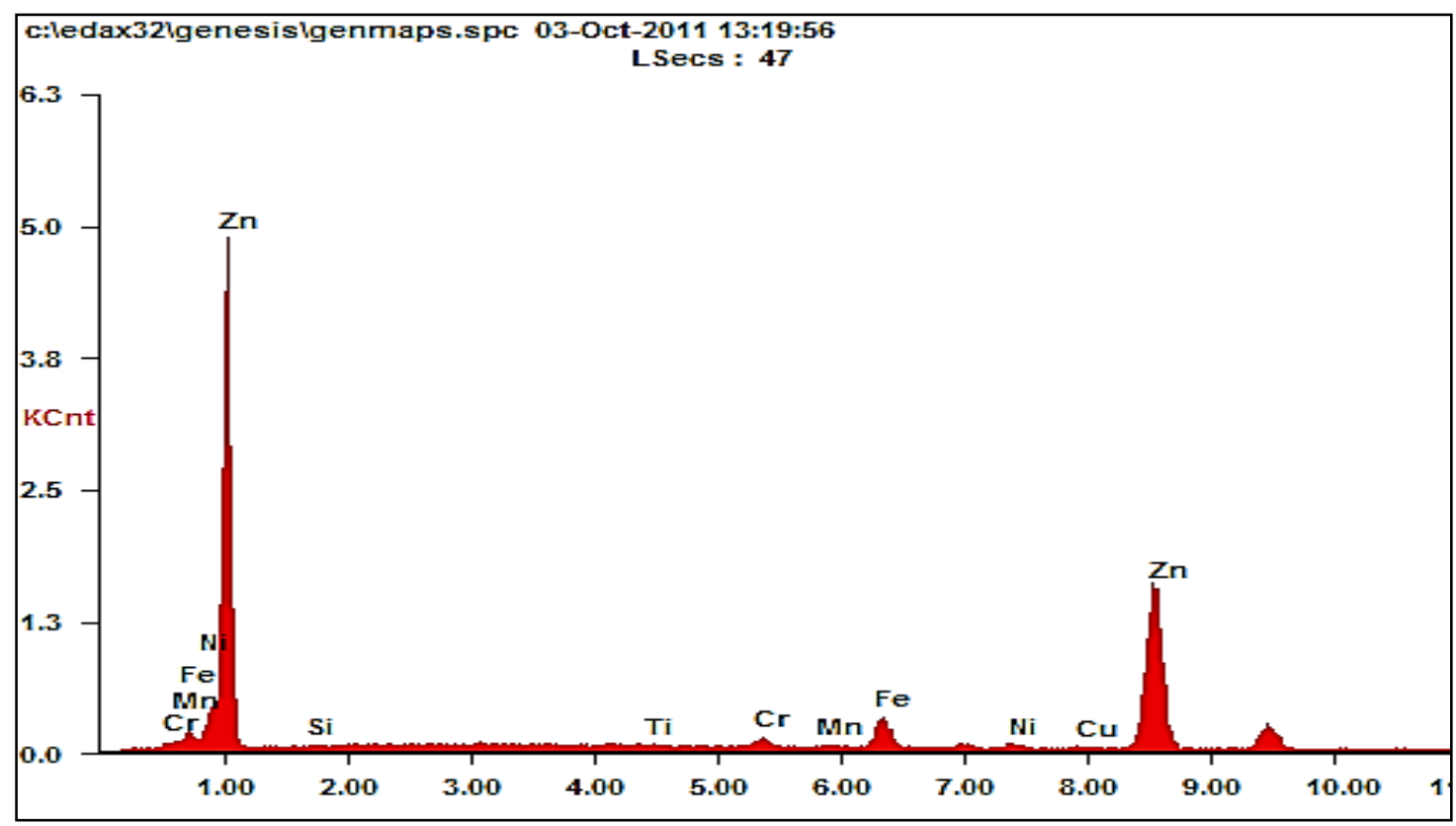

Fig.4: XRD surrounding rod treated 


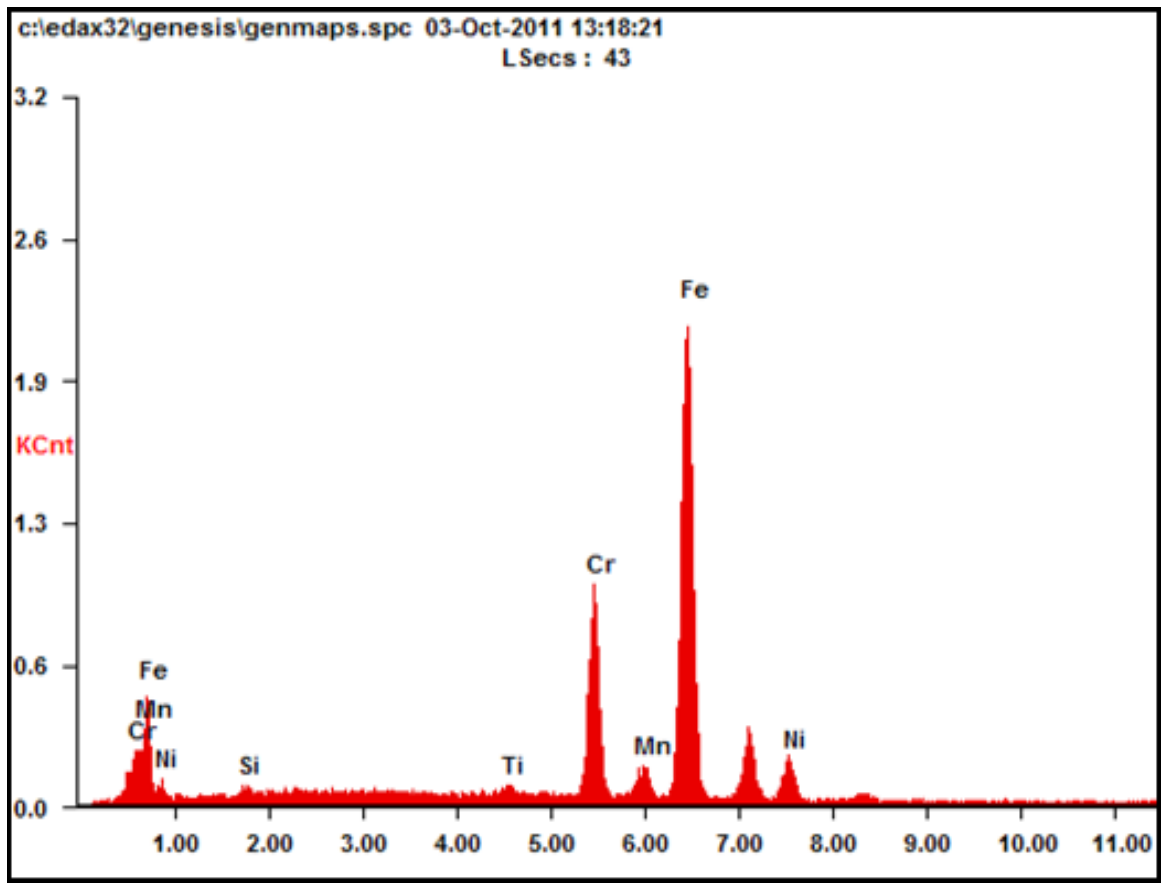

Fig.5 XRD heat treated st . steel rod

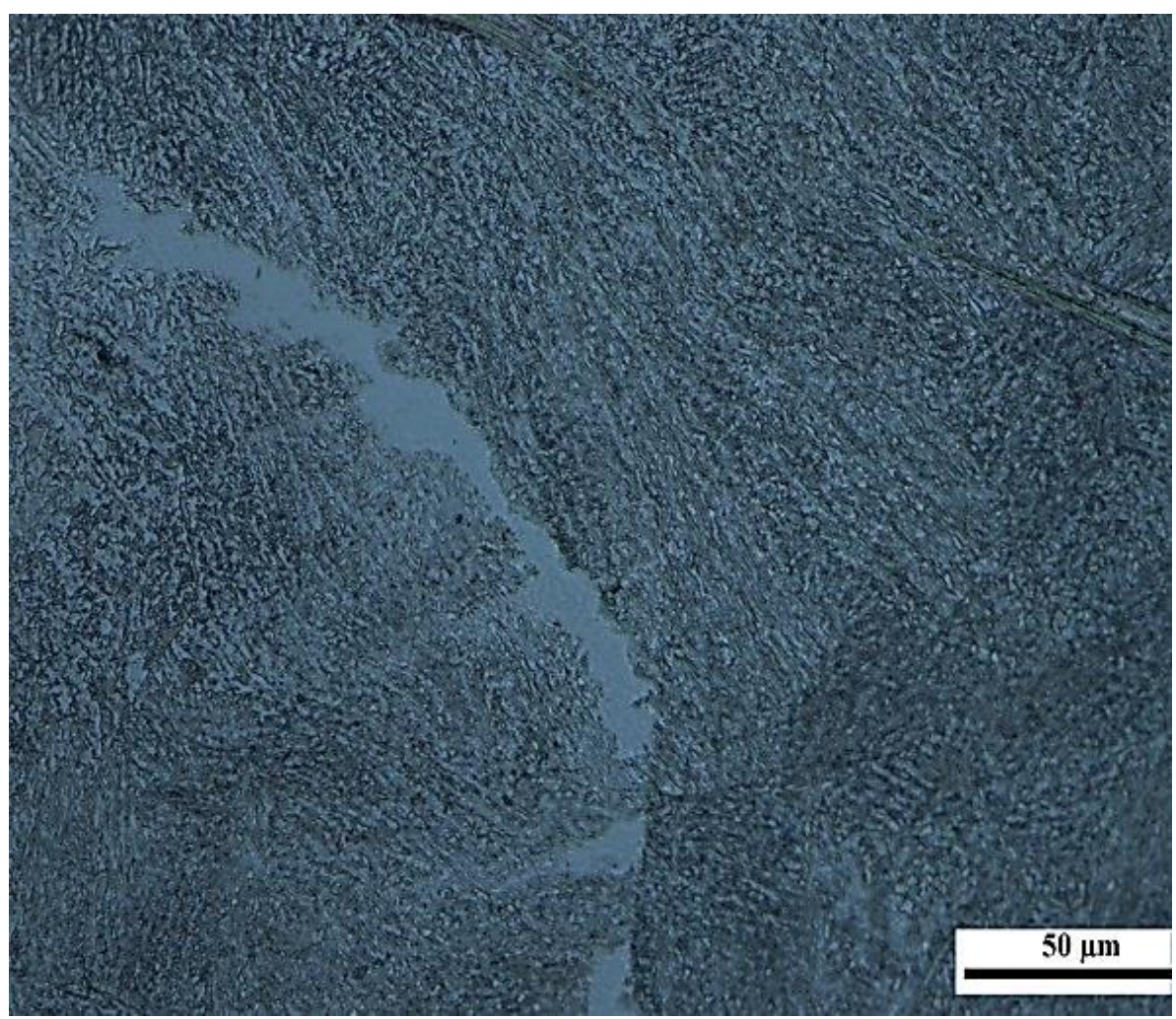

Fig.6 Martensitic stainless-steel 


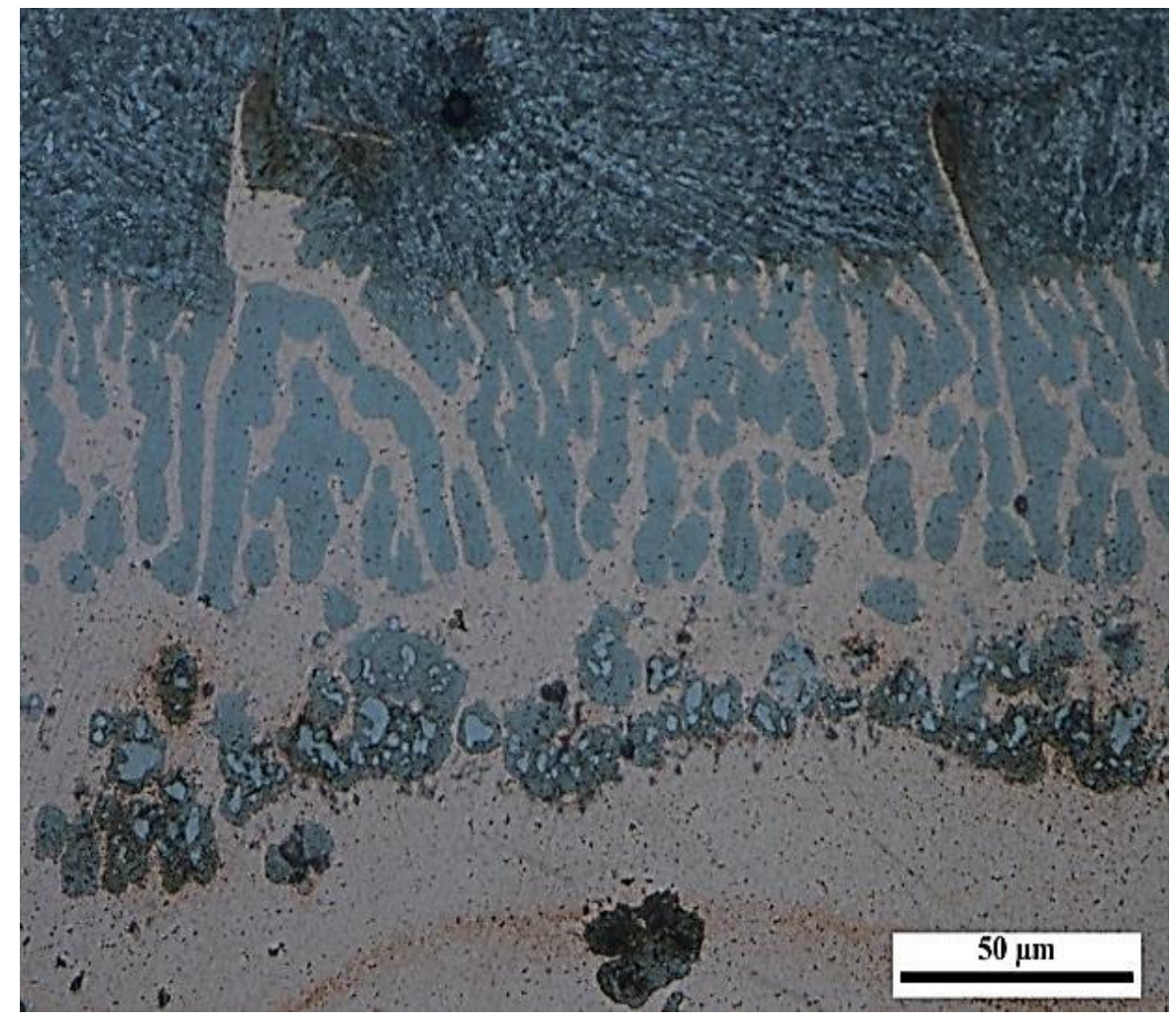

Fig.7 diffusion $\mathrm{Zn}$-cu in rod 